\title{
Nonverbal Communication of Supervisors in the Mentoring Thesis Process: Perceptions of English Students
}

\author{
Meilan Nirmala Shinta (Corresponding author) \\ Shintameilan81@gmail.com \\ Halu Oleo University, Kendari, Indonesia \\ Besse Darmawati \\ bessedarmawaty@gmail.com \\ Balai Bahasa Sulawesi Selatan, Makassar, Indonesia
}

\begin{abstract}
The study examines students' perceptions on the thesis mentoring process regarding their nonverbal communication patterns in the English study program, FKIP of Halu Oleo University. The scope and focus are kinesics, proxemics, oculesics, chronemics, paralanguage, and physical appearance.This study apply a qualitative approach. The data obtained employing interview and documentation are then analyzed by Miles and Huberman's theory using reduction, reporting, and verification. The subjects of the study are eight graduated students and two students in the mentoring process. The study results shows that the six types of nonverbal which are most likely to be experienced more often and influentially are 'kinesics', which is like the supervisor's attitude serving the students. Other nonverbal types continue to take on roles but are not as influential as kinesics. This study reveals that the importance of communication is able to increase student attention and motivation in constructing ideas gained from their supervisors when the communication process is going well and vice versa.
\end{abstract}

Keywords: nonverbal communication; students' perception; thesis mentoring

\section{A. INTRODUCTION}

The importance of 'communication' in learning or classroom environment was just one of the many domains we usually encounter and meet. This opinion is reinforced by (Indrawan et al., 2017; Ranta \& Harmawati, 2017; Lustig, Myron W, 2010). They generally stated that communication is an essential contact for all human and an integral part of human life. People communicate in different ways to express their thoughts, feelings, knowledge, skills, and ideas we wish to convey and understand the message. Therefore, all experts develop communication into two forms, namely verbal and nonverbal communications. 
In particular, verbal communication uses words in conversation or speech to provoke students' feeling, specific emotion, and distinct function in their comments to penetrate their students, instead of nonverbal communication is wordless communication (Lustig, Myron W, 2010). Thus, in this study, the researchers focus on nonverbal communication only due to the aim to find a comprehensive explanation of English students' perception of nonverbal communication supervisors in the mentoring thesis process.

Nonverbal communication was an interdisciplinary field of science. In linguistics and applied linguistics, this science can be a part of intercultural competence (cross culture understanding) discourse analysis because it analyzes the communication process according to its context and relates to general communication science from several references. It has been mentioned clearly by Mahmud (2017) and Lusting and Koester (2010). In the nonverbal communication section, especially for teaching English as a foreign language in the classroom, this type of communication process always accompanies verbal communication such as body language, eye contact, facial mimic, body posture, dressing style, voice intonation, and others. This condition is following the opinion of Negi (1970).

In terms of meaning, some opinions from experts/scholars do not explicitly categorize nonverbal communication, but they only explain per small parts. As a result, from their description, it can be concluded that the process of non-verbal communication, if seen more deeply, can be interpreted from three sides (Mandal, 2014; Patterson, 2016). First, the use of types of communication. This is related to the context such as time, interlocutor or communication, and place (Mahmud, 2017). Second, nonverbal communication reveals body movements and is also referred to as nonlinguistic, in which each type is carried out to convey someone's meaning to others without verbal language (Buck \& VanLear, 2002; Ranta \& Harmawati, 2017). This is interpreted as a media representing the message as well. Third, nonverbal communication has various functions and roles in affecting the meaning of the nonverbal communication process: accent, complement, contradictory, regulates, or substitute for verbal messages (Lustig, Myron W, 2010).

Nonverbal communication in terms of the types is indeed diverse. Each expert, including the researchers here, also classify it varied; for example, Lustig and Koester 
(2010) sorted them (emblems, adapters, effect displays, chemical fragrance, regulators, etc.) much more diverse and detailed. From other experts, the justification for mentioning nonverbal communication in groups is more straightforward. Knap (1972) stated that the ways of nonverbal communication could be different in to nine types, namely (1) bodily contact, which is in the form of touching; (2) proxemics, that is the ways of approaching someone; (3) orientation, that is how to face someone; (4) appearance, that is in the form of hair, clothes, skin, height, weight, etc.; (5) head nods; (6) facial expressions such as eyebrow position, eye shape, mouth shape, and nostril size; (7) gestures of the hand and arms; (8) posture in the forms of sitting, standing, and lying; and (9) eye movement and eye contact. On the other hand, Barabar and Kivanc (2016) explained nonverbal communication into seven types. First, kinesics is a nonverbal message applied in the form of sign language by members of the body such as facial, hand, and head expression as supported by various experts' opinions (Lustig, Myron W, 2010) and (Kendon, 2018). Second, proxemics is related to space divided into four spatial meanings, namely intimate, social, personal, and public space (Ballendat et al., 2010; Danesi, 2006; Greenberg et al., 2011). Third, oculesics is body language that is more language-focused on eye contact (Cruz, 2001; Sullivan, 2012). Fourth, haptics is a nonverbal language that concerns physical contact, for example, shaking hands, touching, and others (Frati \& Prattichizzo, 2011; Indrawan et al., 2017; Schneider et al., 2017). Fifth, chronemic refers to the use of time (Döring \& Pöschl, 2017). Sixth, paralanguage is a nonverbal language that relates to voice intonation. Seventh, physical appearance includes the appearance of a person's body, for example, weight, thin, beautiful, and others (Luangrath et al., 2017; Poyatos, 2002).

Nonverbal communication was an exciting thing because it was said to be a silent language without words. Still, its impact and role have a more significant influence in interpreting the verbal language itself. Therefore, nonverbal studies have been carried out by many experts and scholars. Peng Hong Li (2011) reported that most researchers have found that it is necessary for teachers to learn in using nonverbal behaviour to enhance classroom teaching quality. They found that $82 \%$ of the notions used in a classroom by the teacher are nonverbal, while only $18 \%$ are verbal. To convey the $18 \%$ verbal message better to students, Qi Pan argued that some research findings are concerned with verbal fashion, while some are from what is observed nonverbally. 
Nonverbal communication is only one facet of the giant field of communication, and yet it has been claimed that $65 \%$ of meaning is conveyed through nonverbal communication (Pan, 2014).

Almost all previous studies have concluded that the benefits of nonverbal communication in the classroom context increased student motivation in learning. It means that it can be interpreted as an influential domain role because, implicitly, there is a character-building that the teacher wants to build and shape the educating process. The different side of this study lies in the communication process in students and supervisors' thesis coaching process. The two-way communication model will describe another situation that is different when the process occurs between one lecturer and the number of collective students in the class. This study refers to the types of nonverbal communication by Barabar \& Caganaga (2016): kinesics, proxemics, oculesics, haptics, chronemics, paralanguage, and olfactics, and physical appearance.

The thesis was the final task that students must carry out to obtain their degree. Based on interviews conducted with students who are preparing a thesis, many finalyear students have difficulties compiling a thesis, including finding and formulate problems, determining the title, composing a research proposal, arranging thesis systematics, and others alike. Thesis guidance/mentoring is a means for students to get direction, assistance, advice, and correction of the thesis that is being compiled. Currently, thesis guidance can be done in various ways. Students do not have to meet face-to-face, but they can also use electronic media to communicate, such as mobile phones and the internet. So, students can do thesis guidance via message, telephone or chatting application. Besides, to save expenses, significantly to reduce the costs used to print the draft thesis, students can send their thesis files via email.

Due to the previous explanations of the importance of nonverbal communication in the learning environment, the researchers then formulated the question in the study: how is the process of nonverbal communication between supervisors and students and the impact of nonverbal communication on students' guidance? In line with this, the purpose of this study was to provide information and describe the types of nonverbal communication in the context of thesis guidance and to explore and strengthen the impact of nonverbal communication on students' guidance. 


\section{B. RESEARCH METHOD}

The design of this study was descriptive qualitative design, where the entire contents of the data were presented verbally without quantifying the numbers and analyzed based on the findings obtained for the detailed meaning of the strings (Moleong, 2017); (Atmowardoyo, 2008); (Creswell, 2012). The subjects of the study were students who are categorized as students and have passed or guided their thesis. There is ten number of participants. All students are they who consist of different classes, namely students of 2015, 2016 and 2014.

Data were gathered by using interview techniques (in-depth interview) with the same procedures. Interview data obtained by email media and contact, each student, is given or sent several questions (indirect interview). On the other hand, the researchers were doing direct interviews when contact is done. Students are free to answer freely according to the category of questions after they answer. The researchers were passive observers because the data was gathered through the students' or respondents' photos or documentation of their attendance consultations.

Data were analyzed according to the stages of Miles and Huberman (2014). The analysis consisted of three activities that coincided, (1) data reduction, (2) data presentation, and (3) conclusion/verification. In the stage of data reduction, data were gathered from the respondents' answers. It then was reviewed based on the types of nonverbal communication by making columns that have been labelled respectively. The opinions of respondents who are not under the classification of nonverbal communication are not included in the type group but become a reference in the explanatory factors. In the data presentation stage, the data set that has been grouped then be reviewed to be described in tabular form to facilitate the description of the data after going through the data interpretation and analysis process. Lastly, in the stage of conclusion or verification, before the results of the data analysis conclude, the researchers compare and clarify the data that has been verified with respondents, relevant research, relevant references to the lecturers who are experts in the field of nonverbal or verbal communication in the teaching of language. Through this process, the conclusions begin summarized. 


\section{FINDINGS AND DISCUSSION}

\section{Findings}

The following table described the example of nonverbal communication employed by both supervisors and their students in their interaction.

Table 1. Types of nonverbal communication

\begin{tabular}{lll} 
Types of nonverbal & \multicolumn{1}{c}{ More preferable } & \multicolumn{1}{c}{ Less disliked } \\
\hline Kinesics & Smile, friendly, interactive & $\begin{array}{l}\text { Less interactive, less } \\
\text { friendly and smell }\end{array}$ \\
\hline Proxemic & Smile, friendly, interactive & $\begin{array}{l}\text { Lectures' room, at lecture's } \\
\text { home, classroom }\end{array}$ \\
\hline Oculasic & Eye contact & $\begin{array}{l}\text { Not too eye-to-eye (more } \\
\text { focus on } \\
\text { scribbling/revising thesis) }\end{array}$ \\
\hline Chronemic & In the morning & $\begin{array}{l}\text { In the afternoon and } \\
\text { evening }\end{array}$ \\
\hline Paralanguage & $\begin{array}{l}\text { Moderate (not high or low } \\
\text { intonation) }\end{array}$ & $\begin{array}{l}\text { Intonation voice is high or } \\
\text { too low }\end{array}$ \\
\hline Olfactic & Clean and tidy & Look less neat \\
\hline Physical appearance & Clean and polite & \\
\hline
\end{tabular}

There were ten students as participants, eight students had passed the thesis mentoring process, and two were in the process. Data interpretation in table 1 above illustrated six types of nonverbal communication, those are (1) kinesics, (2) proxemics, (3) chronemics, (4) paralanguage, (5) olfatics, and (6) physical appearance. All these types would describe one by one as a whole.

First, kinesics showed that all participants shared friendly, smiling, and interactive facial expressions in the coaching process, which made students motivated and felt comfortable in communication, particularly in expressing their opinions. On the contrary, all participants who shared a view on communication that showed an unfriendly attitude, flat or cold, and not enthusiastic or no interactive harmed students in expressing their opinions. Second, the type of proxemics illustrated that there are variations in answers, including dominant students, prefer the consultation process to occur in the private lecturer room because the impact can make them more focused. However, some feel comfortable consulting collective lecturers or shared spaces like seminar rooms because they thought similar phases were seen from other friends (regarding the same boat). On the other hand, several rooms make students less 
comfortable, such as on the street, in the classroom, and at home. These places made the lecturers' concentration not so harmful in improving the thesis because it is divided by the interests of other lecturers. Third, chronemics related to the dominant time usage in the morning due to the mood effects for supervisors and students in still fresh members and accept input. Fourth, paralanguage referred to terms of voice intonation. Some students choose moderate but clear voices because they seem to communicate well. High intonation sounds made students afraid or discouraged from consulting, while small voices confused students because it is rather difficult to digest or receive information well. Fifth, olfactics is related to dominant students. Students preferred their supervisor to look clean and neat because the coaching process is better. On the other hand, a tangled appearance made students think of a personality that cannot be emulated mostly in a formal situation. Sixth, physical appearance related to the outside appearance of lecturers for students is not a problem in the lecturer's body shape, face shape or the like because the main thing is the integrity of the lecturer and the lecturer's personality more than just the external appearance.

\section{Discussion}

Students and supervisors sent and received both consciously and unconsciously a lot of nonverbal message cues in the mentoring process. Supervisors expressed many messages through facial expression, vocal intonation, gestures, and the use of space. The realization of nonverbal communication in mentoring interaction in lectures and students perspectives was in the forms of nonverbal immediacy behaviours and nonverbal behaviours accompanying verbal messages. Nonverbal immediacy behaviours include kinesics, proxemics, paralanguage, and chronemics in interpersonal attitudes' nonverbal communication. The supervisor mostly employed some nonverbal cues such as positive responses or vice versa. Those were expressed in some gestures while talking to proxemics context, for instance, in a classroom, lectures or supervisor room, or others. It was typical that students in EFL communication through gestures and cues are essential.

The supervisors used their body language to help students understand the information, messages, or instructions. They used appropriate gestures to transmit their minds. For instance, when a lecture wanted to show their enthusiasm, they expressed their expressions of the face, readiness of physical appearance to serve time and 
themselves by transmitting their ideas. It is indicated that focusing on eye contact is known as the meaning of severe attention or supervising process. The impact could make the communication process run well, and students' response in understanding the guidance is better.

On the other hand, it was considered as obstacles in nonverbal cues when in the mentoring process. For instance, lack of positive responded by the lectures, posture of olfactics (good/bad looking, how to dress neatly and cleanly), and the intonation of voice would not be precise, selecting the inappropriate place and time in the mentoring process, and others. Therefore, lectures or supervisors knew how to utilize different facial expressions to deal with different situations in mentoring to create an excellent consulting atmosphere and enhance their positive communication effect. For instance, when a student gave a wrong answer, the lectures encouraged their students to smile. The lectures or supervisors need to keep students enthusiastic and joyful in the mentoring process. A warm smile could give students felt comfortable studying. To do this, some teachers made some jokes. Hence, lecturers or supervisors and students kept their relationships in a comfortable and relaxing atmosphere. The appropriate distance between interlocutors was considered as positive feedback and communication. In their interaction, the teachers were standing in different positions at the proper distance to make students feel attentiveness and thoughtfulness.

As the research subject, all the students argued that used vocal varieties by the lectures when talking interaction was also essential to make the mentoring process more conducive. They realized that the role of paralinguistic features in the communication process was also important. The paralinguistic component refers to how to say the words, the tone, pacing and volume of voices, and sentence stress. Some lectures or supervisors employed inappropriate paralanguage by using law tone and volume. It made the students felt ambiguous and confusing to receive their supervisors' input and correction. These nonverbal messages had been shown to stimulate meanings of attentiveness and responsiveness. The students showed positive nonverbal communication clues when they directly responded to their supervisors' instruction or input without any objections. The students tended to employ positive communication and give respect and feel close to their lectures or supervisors. 
Moreover, the limitation of the linguistic ability of students had contributed to produce nonverbal expression. Sometimes, the students used silent expression in their responses to their lectures response or attitudes because of inadequate nonverbal cues. Nonverbal behaviours accompanying verbal messages were other vital consideration in this study. There was a tendency to be more communicative if a verbal message is accompanied by nonverbal messages, and both should be congruent. Besides, nonverbal messages accompanying verbal message could emphasize, support, substitute, add, and complement the intended message. Appropriateness of verbal expression can be measured from the etiquette of nonverbal behaviour going along with it. In verbal terms, a good communication process in different speech acts employed by the lectures or supervisors and students in mentoring interaction was mostly emphasized and supported with appropriate nonverbal expressions in various behaviours.

\section{CONCLUSION}

In conclusion, this study's results have similarities in previous studies related to verbal and nonverbal communication. The result showed that nonverbal communication impacts two things, namely, positive and negative effects. Positive impact in improving communication; on the contrary, the communication process's adverse effects did not work well because student motivation decreased as students' intensity to consult with their supervisor. They became hampered and could require more duration long ago. It arrived at the level of completion of the student.

\section{REFERENCES}

Atmowardoyo, H. (2008). Metode Penelitian Kualitatif: Teori Dasar. Badan Penerbit UNM.

Aysenil, Barabar; Cagda Kivanc, C. (2016). Using Nonverbal Communication in Efl Classes Aysenil. January.

Ballendat, T., Marquardt, N., \& Greenberg, S. (2010). Proxemic interaction: Designing for a proximity and orientation-aware environment. ACM International Conference on Interactive Tabletops and Surfaces, ITS 2010. https://doi.org/10.1145/1936652.1936676

Buck, R., \& VanLear, C. A. (2002). Verbal and nonverbal communication: Distinguishing symbolic, spontaneous, and pseudo-spontaneous nonverbal behavior. Journal of Communication. https://doi.org/10.1093/joc/52.3.522

Creswell, J. W. (2012). Educational Research: Planning, Conducting and Evaluating, Quantitative and Qualitative Research.

Cruz, W. (2001). Differences in nonverbal communication styles between cultures: The latino-anglo perspective. Leadership and Management in Engineering. 
https://doi.org/10.1061/(ASCE)1532-6748(2001)1:4(51)

Danesi, M. (2006). Proxemics. In Encyclopedia of Language \& Linguistics. https://doi.org/10.1016/B0-08-044854-2/01441-3

Döring, N., \& Pöschl, S. (2017). Nonverbal cues in mobile phone text messages: The effects of chronemics and proxemics. In The Reconstruction of Space and Time: Mobile Communication Practices. https://doi.org/10.4324/9781315134499-6

Frati, V., \& Prattichizzo, D. (2011). Using Kinect for hand tracking and rendering in wearable haptics. 2011 IEEE World Haptics Conference, WHC 2011. https://doi.org/10.1109/WHC.2011.5945505

Greenberg, S., Marquardt, N., Ballendat, T., Diaz-Marino, R., \& Wang, M. (2011). Proxemic interactions. Interactions. https://doi.org/10.1145/1897239.1897250

Hong Li, P. (2011). Effects of Nonverbal Communication on College English Classroom Teaching. US-China Foreign Language, 9(8), 505-516.

Indrawan, I. P., Nitiasih, P. K., \& Piscayanti, K. S. (2017). an Analysis of Teachers' Non-Verbal Communication in Efl Classroom At Smp Negeri 3 Banjar. Prasi, 12(01), 1-11. https://doi.org/10.23887/prasi.v12i01.13912

Kendon, A. (2018). Review of birdwhistell 's 'kinesics and context .' January 1972.

Knapp, M. L., \& Hall, J. A. (1972). Nonverbal communication in human interaction. In Dress as NonVerbal Communication.

Luangrath, A. W., Peck, J., \& Barger, V. A. (2017). Textual paralanguage and its implications for marketing communications. Journal of Consumer Psychology. https://doi.org/10.1016/j.jcps.2016.05.002

Lustig, Myron W, J. K. (2010). Intercultural Competence: Interpersonal Communication Across Cultures.

Mahmud, M. (2017). Doing Discourse Analysis: An Introduction. Phoenix Publisher.

Mandal, F. B. (2014). Nonverbal Communication in Humans. Journal of Human Behavior in the Social Environment. https://doi.org/10.1080/10911359.2013.831288

Matthew B.M., A.M Huberman, Saldana, J. (2014). Qualitative Data Analysis. Sage Publication,Inc.

Moleong, L. J. (2017). Metodologi Penelitian Kualitatif. Remaja Rosdakarya.

Negi, J. S. (1970). The Role of Teachers' Non-Verbal Communication in ELT Classroom. Journal of NELTA. https://doi.org/10.3126/nelta.v14i1.3096

Pan, Q. (2014). Nonverbal Teacher-Student Communication in the Foreign Language Classroom: Theory and Practice. English Language Studeis, 4(12), 2627-2632.

Patterson, M. L. (2016). Nonverbal communication. In The Curated Reference Collection in Neuroscience and Biobehavioral Psychology. https://doi.org/10.1016/B978-0-12-809324-5.06502-0

Poyatos, F. (2002). Nonverbal Communication across Disciplines: Paralanguage, kinesics, silence, personal and environmental interaction. In Notes.

Ranta, R., \& Harmawati, D. (2017). Analyzing Teacher'S Instructional and Nonverbal Communication in Efl Classroom. Lingual: Journal of Language and Culture, 4(2), 26. https://doi.org/10.24843/ljlc.2017.v04.i02.p05

Schneider, O., MacLean, K., Swindells, C., \& Booth, K. (2017). Haptic experience design: What hapticians do and where they need help. International Journal of Human Computer Studies. https://doi.org/10.1016/j.ijhcs.2017.04.004 
Meilan Nirmala Shinta \& Besse Darmawati

Available Online at https://journal.iaingorontalo.ac.id/index.php/al

Sullivan, L. (2012). Oculesics. In The SAGE Glossary of the Social and Behavioral Sciences. https://doi.org/10.4135/9781412972024.n1752 